\title{
PENINGKATAN LOYALITAS NASABAH BANK SYARIAH MELALUI PENINGKATAN KUALITAS LAYANAN DAN KEPUASAN NASABAH DENGAN VARIABEL RELIGIUSITAS SEBAGAI VARIABEL MODERATING (Studi pada Bank Syariah di Kota Semarang)
}

\author{
Nurhayati \& Fatmasaris Sukesti \\ Universitas Muhammadiyah Semarang \\ ezzy.nurhayati@gmail.com \& fatmasaris@yahoo.com
}

\begin{abstract}
Competitive rivalry between conventional banks and Islamic banks make Islamic banks should be able to compete with conventional banks in providing good quality of service, product quality and customer satisfaction, thereby increasing the number of customers. Quality of service also can affect customer loyalty directly and indirectly. The quality of service and satisfaction to encourage customers to be loyal to a company's products and services that have an impact on the improvement of market share for a product. Quality of service and customer satisfaction, especially in service companies is very important in retaining customers in a long time. Quality of service and customer satisfaction will determine the performance of the company. Factors religiosity in Indonesia also played in determining and pushing for elections on islamic bank customers because the system for different results offered by the system of interest of conventional banks. These results indicate that the quality of service and level of customer satisfaction and religiosity jointly effect on customer loyalty. Quality of service and customer satisfaction levels also have an effect on customer loyalty which variabels most influence on customer loyalty is the degree of religiosity.
\end{abstract}

Keywords: service quality; customer satisfaction; religiosity; customer loyalty.

\section{Pendahuluan}

Perkembangan bank syariah di Indonesia secara umum cuku menggembirakan. Ini ditandai dengan semakin dikenalnya bank syariah maupun dengan meningkatnya kinerja bank syariah nasional. Menurut Ihsan Mojo, peneliti INDEF, perkembangan bank syariah di Indonesia telah on the track. Semakin berkembangnya bank syariah di Indonesia dan dunia antara lain disebabkan oleh kemampuan bank syariah ketika menghadapi krisis 
keuangan. baik krisis keuangan tahun 1998 maupun krisis keuangan tahun 2009, dimana banyak bank konvensional kolaps sedangkan bank syariah tetap bertahan. Berbagai faktor yang menentukan berkembangnya bank syariah di Indonesia salah satunya adalah faktor demografi dimana penduduk di Indonesia 87\% adalah beragama Islam. Tetapi pengaruh factor-faktor lain misalnya faktor kualitas produk perbankan, faktor layanan, faktor promosi, dan kepuasan nasabah ikut menentukan diterimanya bank syariah di masyarakat.

Daya tarik bank syariah terdapat pada perbedaan pemberian keuntungan bank kepada nasabah dengan sistem bagi hasil dan pelayanan memiliki keterkaitan yang paling erat dengan karakteristik konsumen sebagai salah satu alasan agar nasabah tetap memilih jasa perbankan syariah sebagai alternatif utama dalam menabung.promosi, dan kepuasan nasabah ikut menentukan diterimanya bank syariah di masyarakat. Daya tarik bank syariah terdapat pada perbedaan pemberian keuntungan bank kepada nasabah dengan sistem bagi hasil dan pelayanan memiliki keterkaitan yang paling erat dengan karakteristik konsumen sebagai salah satu alasan agar nasabah tetap memilih jasa perbankan syariah sebagai alternatif utama dalam menabung.

Dalam penelitian Nurafifah dan Haron ${ }^{1}$ tentang persepsi konsumen di Malaysia terhadap bank syariah terdiri beberapa dimensi yaitu pemanfaatan fasilitas perbankan, pengetahuan terhadap perbankan Islam, peranan konsumen dalam memilih produk perbankan. Hal ini dapat disimpulkan bahwa pentingnya persepsi atau perilaku nasabah dalam memengaruhi keputusannya untuk memilih jasa perbankan syariah.

Kedudukan perbankan syariah mendapatkan dukungan dengan disahkannya UU tentang Perbankan Islam, yaitu UU No. 21 Tahun 2008. Undang-undang dengan 13 bab dan 70 pasal yang disahkan oleh Presiden Susilo Bambang Yudhoyono (16 Juli 2008) ini diharapkan dapat mempercepat akselerasi perkembangan perbankan Islam, sehingga diharapkan pada 2012 pangsa pasar perbankan Islam telah mencapai 5\% dari pangsa pasar perbankan secara nasional.

\footnotetext{
1 Nurafifah dan Haron, "Perception of Malaysian Corporate Consumers Towards Islamic Banking Products", International Journal of Islamic Finance Service, Vol. 1, No. 4, 2001.
} 
Tetapi perkembangan bank syariah tidak terlepas dari iklim kompetisi dalam dunia perbankan antara bank konvensional dan bank syariah. Di sisi lain, perubahan lingkungan yang demikian pesat semakin mendukung kompetisi yang sedang terjadi saat ini. Salah satu indikator keberhasilan seringkali dilihat dari pencapaian loyalitas pelanggan melalui strategi pemasaran dan kepuasan pelanggan dalam hal ini adalah nasabah bank. ${ }^{2}$ Loyalitas pelanggan merupakan bagian terpenting pada pengulangan pembelian pada pelanggan. ${ }^{3}$

Menurut Beerli, dkk ${ }^{4}$ loyalitas pelanggan memiliki korelasi yang positif dengan performa bisnis suatu perusahaan. Loyalitas pelanggan tidak hanya meningkatkan nilai dalam bisnis, tetapi juga dapat menarik pelanggan baru. Pada jangka pendek, memperbaiki loyalitas pelanggan akan membawa profit pada penjualan. Profit merupakan motif utama dalam bisnis, dengan keuntungan maka roda perputaran bisnis dan produk maupun jasa yang ditawarkan dikembangkan serta malakukan perluasan pasar yang dilayani. Dalam jangka panjang, memperbaiki loyalitas umumnya akan lebih profitabel, yakni pelanggan bersedia membayar harga lebih tinggi (pada pembeli yang sudah loyal), penyediaan layanan yang lebih murah dan bersedia merekomendasikan ke pelanggan yang baru (words of mouth marketing).

Menurut Zeithaml dkk, ${ }^{5}$ kualitas layanan juga dapat memengaruhi loyalitas pelanggan secara langsung dan tidak langsung. Kualitas layanan mendorong pelanggan untuk setia kepada produk dan layanan suatu perusahaan sehingga berdampak kepada peningkatan market share suatu produk. Kualitas layanan terutama pada perusahaan jasa sangat penting dalam mempertahankan pelanggan dalam waktu yang lama. Kualitas layanan akan menentukan performa perusahaan.

\footnotetext{
2 Nurhayati Siregar, Analisis Faktor-faktor Yang Mempengarubi Penyaluran Dana Perbankan Syariah di Indonesia, Tesis (dipublikasikan), Medan: Program Pascasarjana Universitas Sumatra Utara, 2004

3 Albert Caruana, "Service Loyalty: The Effect of Service Quality and The Mediating Role of Costomer Satisfaction”, European Journal of Marketing, Vol. 36, No. 7/8, 2002, pp. 811-828.

${ }^{4}$ Beerli a, dkk, "A Model of Customer Loyalty in the Retail Banking Market, European Journal of Marketing, Vol. 38, No. 1/2, 2004, pp. 253-275.

${ }^{5}$ Zeithaml, dkk, Services Marketing, 1st edition, New York: Mc GrawHill, 1996
} 
Peningkatan Loyalitas Nasabah...

Pentingnya peran bank syariah dalam perekonomian di Indonesia, mendorong berbagai upaya peningkatan dan pengembangan bank syariah yang didukung faktor perbaikan kualitas layanan dan kepuasan pelanggan atau nasabah yang akan meningkatkan loyalitas nasabah bank syariah. Kemudian berkenaan dengan prospek perbankan syariah ke depan, diharapkan masih bertumbuh dan prospektif, tercermin dari pengembangan pasar yang masih besar di dalam negeri.

Selain itu, optimisme dunia internasional terhadap perbankan syariah Indonesia masih cukup tinggi. Hal ini tampak dari penilaian Ernst \& Young dalam World Islamic Banking Competitives Report 2013-2014 maupun UKs Global Islamic Finance Report 2013 bahwa keuangan syariah Indonesia adalah termasuk ke dalam rapid growth market dan dynamic market, serta telah menjadi referensi pengembangan keuangan syariah maupun berpotensi sebagai salah satu pendorong keuangan syariah dunia.

Berdasarkan rumusan masalah di atas, tujuan utama dari penelitian ini adalah: (1) menganalisis pengaruh kualitas layanan terhadap loyalitas nasabah, (2) menganalisis pengaruh kepuasan nasabah terhadap loyalitas nasabah, dan (3) menganalisis pengaruh religiusitas terhadap loyalitas nasabah

\section{Kerangka Teoritis dan Hipotesis}

Berdasarkan telaah pustaka di atas bahwa loyalitas nasabah dipengaruhi oleh kualitas layanan dan kepuasan pelanggan kepada bank syariah, sedangkan religiusitas menunjuk pada aspek agama yang telah dihayati oleh seseorang dalam hati, di mana keyakinan agama seseorang yang percaya bunga bank itu haram dapat menyebabkan nasabah bank memberikan alternatif pilihannya pada bank syariah. Dan variabel religiusitas ini yang memoderasi pada variabel kualitas layanan dan kepuasan nasabah terhadap loyalitas nasabah pada bank syariah. 


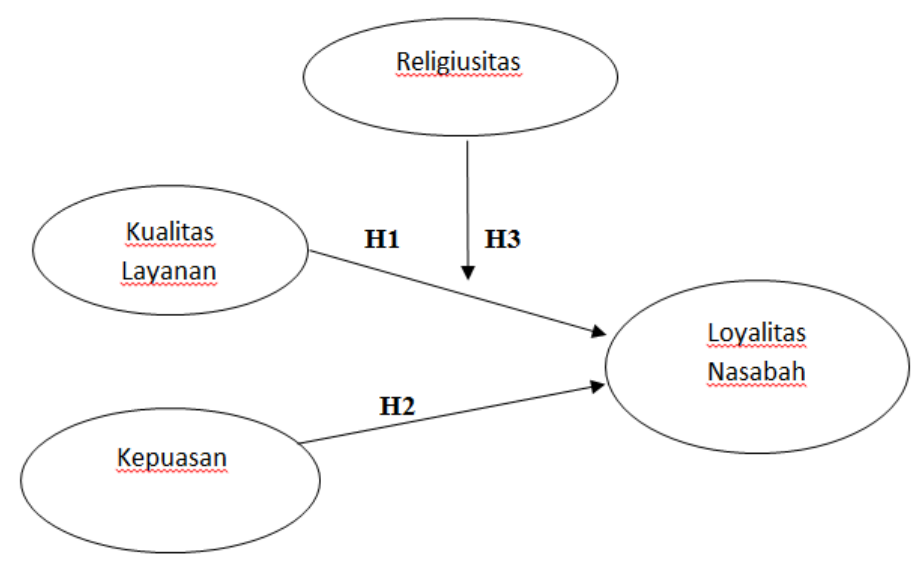

Sumber : Pengembangan Penelitian

Hipotesis-hipotesis yang akan diajukan dalam penelitian ini berdasarkan atas latar belakang, permasalahan, telaah pustaka dan kerangka pemikiran teoritis bahwa variabel dependent loyalitas nasabah dipengaruhi oleh variabel independent kualitas layanan dan kepuasan nasabah serta religiusitas sebagai variabel moderating. Hipotesis yang diajukan adalah:

H1 : Kualitas Layanan berpengaruh pada Loyalitas nasabah

H2 : Kepuasan berpengaruh pada Loyalitas nasabah

H3 : Religiusitas berpengaruh pada Loyalitas nasabah

\section{Metodologi}

\section{Teknik Penarikan Sampel}

Metode penarikan sampel dalam hal ini adalah nasabah bank syariah yang ada di kota Semarang dengan metode random sampling, yaitu teknik sampling dimana peneliti mempunyai pilihan pribadi dalam memilih individu yang akan menjadi anggota sampel.

\section{Besaran Sampel}

Besaran sampel merupakan banyaknya individu, subjek atau elemen dari populasi yang diambil sebagai sampel. Berikut ini rumus yang dapat digunakan untuk mengetahui jumlah sampel minimal untuk sebuah penelitian: 
Peningkatan Loyalitas Nasabah...

Dalam penelitian ini, populasi sasaran adalah sebanyak 100 nasabah Bank Syariah. Jumlah sampel yang harus dipenuhi untuk menguji hipotesis ditentukan menggunakan rumus yang telah didemonstrasikan oleh Rao, ${ }^{6}$ yaitu sebagai berikut:

$$
\mathrm{n}=\frac{\mathrm{N}}{1+\mathrm{N}(\mathrm{moe})^{2}}
$$

di mana: $\mathrm{n}=$ jumlah sampel

$$
\mathrm{N}=\text { jumlah populasi }
$$

moe $=$ margin of error maximum (tingkat kesalahan yang ditolerir), Rao (1996) mengasumsikan moe sebesar 5\%.

Dari rumus tersebut, jumlah sampel yang dibutuhkan dalam penelitian ini adalah sebanyak 100 nasabah Bank Syariah.

\section{Analisis Data}

Kuesioner yang digunakan dalam penelitian ini telah diuji, yakni uji vailiditas dan uji reliabilitas. Untuk mengetahui sejauh mana pengaruh kualitas produk dan tingkat kepuasan konsumen terhadap loyalitas pelanggan, data yang telah terkumpul dianalisis menggunakan analisis regresi.

\section{Hasil dan Pembahasan}

Uji reliabilitas dilakukan dengan cara menghitung besarnya Cronbach Alpha dari masing-masing instrumen dalam suatu variabel, syarat untuk dikatakan reliabel jika memiliki Cronbach alpha $>$ 0,60.7 Tabel 1 menunjukkan bahwa seluruh instrumen dari variabel yang diuji memiliki Cronbach Alpha di atas 0.60. Jadi, hasil pengujian cukup memuaskan karena semua instrumen memiliki tingkat reliabilitas (keandalan) yang tinggi, sehingga dapat dipakai untuk pengolahan data selanjutnya.

\footnotetext{
${ }^{6}$ Purba Rao, "Measuring Consumer Perseption Through Factor Analysis", The Asian Manager, 1996, February-March. 1978.

${ }^{7}$ J.C. Nunnally, Assessment of Reliability In Psychometric Theory (2nd ed.), New York: McGraw-Hill,
} 


\section{Tabel 1}

Hasil Uji Reliabilitas

\begin{tabular}{|l|l|}
\hline \multicolumn{1}{|c|}{ Variabel } & Cronbach alpha \\
\hline Kualitas Layanan (X1) & 0,741 \\
\hline Kepuasan (X2) & 0,802 \\
\hline Religiusitas (X3) & 0,705 \\
\hline Loyalitas nasabah (Y) & 0,801 \\
\hline
\end{tabular}

Sumber : Data primer yang diolah,2016

\section{Uji Asumsi Klasik}

\section{Multikolinearitas}

Gejala multikolinearitas dapat dideteksi dengan melihat tolerance dan nilai variance inflation faktor (VIF). Suatu model regresi dikatakan bebas dari masalah multikolinearitas apabila mempunyai nilai tolerance mendekati 1 dan VIF disekitar 1 (Santoso, 2000). Berdasarkan output SPSS pada table 5.4 terlihat bahwa nilai tolerance menunjukkan angka mendekati 1, sedangkan perhitungan nilai VIF juga menunjukkan hal yang sama, dimana tidak ada satu variabel bebas yang memiliki nilai VIF lebih dari 10. Korelasi antar variabel independen cukup rendah, sehingga dapat disimpulkan bahwa data penelitian ini bebas dari masalah multikolinearitas.

Tabel 2

Hasil Uji Multikolinearitas

\begin{tabular}{|l|l|l|}
\hline Variabel & Tolerance & VIF \\
\hline Kualitas Layanan(X1) & 0,369 & 2,706 \\
\hline Kepuasan (X2) & 0,735 & 1,360 \\
\hline Religiusitas (X3) & 0,427 & 2,342 \\
\hline
\end{tabular}

Sumber: data primer yang diolah, 2016

\section{Autokorelasi}

Dari hasil SPSS diperoleh nilai Durbin Watson sebesar 1,773 yang berada di atas atau lebih besar dari batas dl - du pada tingkat signifikansi $5 \%$. Diketahui dari Tabel Durbin Watson bahwa nilai batas atas $\mathrm{dl}=1,54$ dan du 
Peningkatan Loyalitas Nasabah...

$=1,66$. Hasil pengujian ini menunjukkan bahwa data penelitian bebas dari masalah autokorelasi.

\section{Heteroskedastisitas}

Untuk mendeteksi ada tidaknya gejala heteroskedastisitas, dapat dilihat pada grafik plot antara nilai prediksi variabel dependen dengan residualnya. Jika ditemukan pola tertentu yang teratur pada grafik plot, maka mengindikasikan telah terjadi heteroskedastisitas. Sebaliknya apabila ada titiktitik pada grafik yang tidak membentuk suatu pola tertentu maka tidak terjadi heteroskedastisitas.

Berdasarkan hasil output SPSS dengan melihat hasil plot antara nilai prediksi variabel dependen dengan nilai residualnya menunjukkan pola yang tidak beraturan atau tidak membentuk suatu pola tertentu. Hal ini mengindikasikan tidak terjadinya masalah heteroskedastisitas pada penelitian ini.

\section{Normalitas}

Berdasarkan tampilan grafik histogram dan grafik normal plot dapat disimpulkan bahwa grafik histogram memberikan pola distribusi yang mendekati normal. Sedangkan pada grafik normal plot terlihat titik-titik menyebar di sekitar garis diagonalnya, serta penyebarannya mengikuti arah garis diagonal. Dari kedua macam grafik ini menunjukkan bahwa model regresi layak digunakan karena memenuhi asumsi normalitas.

\section{Uji Hipotesis}

Penelitian ini menggunakan analisis regresi berganda untuk menguji beberapa hipotesa yang diajukan. Ringkasan hasil pengujian regrasi berganda tampak pada tabel sebagai berikut: 


\section{Tabel 3}

Hasil Uji Regresi Berganda

\begin{tabular}{|l|l|l|l|l|}
\hline Variabel & Koefisien B & $\mathbf{T}$ & Signifikansi & Hasil \\
\hline Hipotesa 1 & 0,264 & 2,146 & 0,035 & Diterima \\
\hline Hipotesa 2 & 0,169 & 1,940 & 0,056 & Diterima \\
\hline Hipotesa 3 & 0,431 & 3,772 & 0,000 & Diterima \\
\hline
\end{tabular}

Sumber : Data primer yang diolah, 2016

Hipotesa 1 menyatakan bahwa kualitas layanan berpengaruh positif terhadap loyalitas nasabah tersebut. Setelah dilakukan pengujian hipotesis menggunakan analisis regresi melalui program SPSS, diketahui bahwa hasil pengujian hipotesis 1 adalah positif signifikan pada level $5 \%$ (p $<0,05)$. Dari hasil tersebut maka dapat disimpulkan bahwa hipotesis 1 dapat diterima. Hasil analisis tersebut mengindikasikan bahwa semakin baik kualitas layanan yang diberikan bank syariah kepada nasabahnya maka akan semakin tinggi loyalitasnya pada bank syariah. Kualitas layanan yang baik mencerminkan bahwa bank syariah berorientasi untuk meraih jumlah nasabah yang lebih besar.

Hipotesa 2 menyatakan bahwa kepuasan berpengaruh positif terhadap loyalitas nasabah tersebut. Setelah dilakukan pengujian hipotesis menggunakan analisis regresi melalui program SPSS, diketahui bahwa hasil pengujian hipotesis 2 adalah positif signifikan pada level $5 \%(\mathrm{p}<0,05)$. Dari hasil tersebut maka dapat disimpulkan bahwa hipotesis 2 dapat diterima. Hasil analisis tersebut mengindikasikan bahwa semakin tinggi kepuasan yang diberikan bank syariah kepada nasabahnya maka akan semakin tinggi loyalitasnya pada bank syariah. Kepuasan nasabah mencerminkan bahwa bank syariah memberikan kualitas layanan yang baik dan dapat mempertahankan loyalitas nasabah serta berorientasi untuk meraih jumlah nasabah yang lebih besar.

Hipotesa 3 menyatakan bahwa religiusitas sebagai variabel moderating dapat memoderasi terhadap variabel kulitas layanan terhadap variable loyalitas nasabah tersebut. Setelah dilakukan pengujian hipotesis menggunakan analisis 
variabel moderating, diketahui bahwa hasil pengujian hipotesis 3 adalah positif signifikan pada level $5 \%(\mathrm{p}<0,05)$. Dari hasil tersebut maka dapat disimpulkan bahwa hipotesis 3 dapat diterima. Hasil analisis tersebut mengindikasikan bahwa semakin tinggi tingkat religiusitas seseorang maka variabel religiusitas dapat memoderasi antara kualitas layanan dengan loyalitas semakin tinggi tingkat kepercayaan seorang nasabah untuk memberikan kepercayaan kepada bank syariah maka akan semakin tinggi loyalitasnya pada bank syariah

\section{Kesimpulan}

Berdasarkan hasil penelitian dengan menggunakan program SPSS untuk meneliti peningkatan loyalitas nasabah bank syariah melalui peningkatan kualitas layanan dan kepuasan nasabah dengan variabel religiusitas sebagai variabel moderating, maka diperoleh kesimpulan sebagai berikut:

1. Variabel kualitas layanan, kepuasan nasabah dan religiusitas berpengaruh dan secara bersama sama memengaruhi loyalitas nasabah bank syariah.

2. Diketahui ternyata variabel religiusitas merupakan variabel yang berpengaruh dominan terhadap loyalitas.

Ada beberapa saran yang penulis kemukakan dari hasil penelitian ini, antara lain:

1. Dari perspektif kualitas layanan, maka bank syariah harus tetap menjaga mutu kualitas layanan tersebut, agar mampu menghasilkan pengaruh yang positif terhadap loyalitas pada produk bank syariah.

2. Dari perspektif tingkat kepuasan konsumen yang dinilai sangat positif serta berpengaruh terhadap loyalitas nasabah. Maka bank syariah harus memberikan pelayanan yang lebih baik lagi yang dilakukan oleh pegawai bank syariah dan tetap memberikan pelayanan yang ramah dan sopan terhadap konsumennya.

3. Tingkat religiusitas dari nasabah sangat berpengaruh sekali terhadap loyalitas sehingga jenis produk-produk dari bank syariah harus dipertahankan. 
4. Dari variabel kualitas layanan dan variabel tingkat kepuasan konsumen memiliki pengaruh yang besar terhadap loyalitas pelanggan pada bank syariah.

5. Untuk penelitian selanjutnya, masukan variabel promosi guna mengembangkan hasil penelitian yang telah dilakukan sebelumnya. 


\section{DAFTAR PUSTAKA}

Beerli a, dkk, "A Model of Customer Loyalty in the Retail Banking Market, European Journal of Marketing, Vol. 38, No. 1/2, 2004, pp. 253-275

Caruana, Albert, "Service Loyalty: The Effect of Service Quality and The Mediating Role of Costomer Satisfaction", European Journal of Marketing, Vol. 36, No. 7/8, 2002, pp. 811-828.

Fatmah, "Perilaku Konsumen Muslim", http://id.scribd.com/doc/88590811/ Perilaku-Konsumen-Muslim, diakses 26 Maret 2014.

Jalaluddin, Psikologi Agama, Jakarta: PT. Raja Grafindo Persada, 2010.

Kotler, Philip, Marketing Management: The millenium edition, Ten edition, USA: Prentice Hall, Inc, 2000.

--------, Manajemen Pemasaran 1, Edisi Millenium, Jakarta: PT. Prenhallindo, 2002.

Kotler, Philip, dan Kevin Lane Keller, Manajemen Pemasaran, Edisi Kedua Belas, Jakarta: Indeks, 2007.

Naumann and Kathleen Giel, Customer Satisfaction Measurement and Management, Cincinnati, Ohio: Thomas Executive Press, 1995.

Norafifah Ahmad dan Sudin Haron, "Perceptions of Malaysian Corporate Customers Towards Islamic Banking Products and Services", International Journal of Islamic Financial Services, Volume 3, Number 4, 2001.

Nunnally, J. C, Assessment of Reliability In Psychometric Theory (2nd ed.), New York: McGraw-Hill, 1978.

Parasuraman, A, Valarie A. Zeithaml, and Leonard L. Berry, "SERVQUAL: A Multiple-Item Scale for Measuring Consumer Perceptions of Service Quality”, Journal of Retailing, Vol. 64, No. 1. (1988), pp. 12-40.

Rao, Purba, "Measuring Consumer Perseption Through Factor Analysis", The Asian Manager, 1996, February-March.

Samuel, Hatane dan Nadya Wijaya, "Service Quality, Perceive Value, Satisfaction, Trust, dan Loyalty Pada PT. Kereta Api Indonesia Menurut Penilaian Pelanggan Surabaya", Jurnal Manajemen Pemasaran, Vol. 4, No. 1, 2009, pp. 23-37. 
Siregar, Nurhayati, Analisis Faktor-faktor Yang Memengarubi Penyaluran Dana Perbankan Syariah di Indonesia, Tesis (dipublikasikan), Medan: Program Pascasarjana Universitas Sumatra Utara, 2004.

Tjiptono, Fandy dan Anastasia Diana, Total Quality Manajemen, Edisi Revisi, Yogyakarta: Penerbit Andi Offset, 2003.

Tjiptono, Fandy, Strategi Pemasaran, Edisi Pertama, Yogyakarta: Penerbit Andi Offset, Penerbit Andi Offset.

UU No.21 Tahun 2008 Tentang Perbankan Islam

Woro, dkk, "Pengaruh Nilai Pelanggan dan Kualitas Layanan Terhadap Loyalitas Pelanggan, Melalui Kepuasan Pelanggan Pada Pelanggan Bus Efisiensi”, Jurusan Administrasi Bisnis FISIP Universitas Diponegoro Semarang, Volume 2, Nomor 1, Maret 2013.

Zeithaml, dkk, Services Marketing, 1st edition, New York: Mc GrawHill, 1996. 